\title{
Influence of Slope Aspect on above Ground Biomass Estimation using ALOS-2 Data
}

\author{
Junaid Mushtaq Lone ${ }^{1}$, Thota Sivasankar ${ }^{2 *}$, K K Sarma ${ }^{3}$, Abdul Qadir ${ }^{4}$, P L N Raju \\ ${ }^{1}$ Bharathidasan University, Tiruchirappalli, Tamil Nadu, India \\ 2, 3, 4,5 North Eastern Space Applications Centre, Umiam, Meghalaya, India
}

\begin{abstract}
Synthetic aperture radar data has been extensively used for above ground biomass estimation of forest. The potentials of SAR data for biomass retrieval is well understood and documented in flat surfaces, whereas limited work has been carried in hilly surfaces. This study aims to investigate the influence of slope aspect on above ground biomass estimation using ALOS-2 PALSAR-2 data over Nongkhyllem Forest Reserve and Wildlife Sanctuary, India. Approximately 3 dB difference in the backscattering coefficient has been observed between area facing towards the sensor and shadowed area having specific AGB. Further, early saturation of backscatter in shadowed areas than in the areas facing towards the sensor due to increase in propagation length of signal through vegetation. The HV backscatter has shown high sensitivity towards AGB with $r$ and RMSE of 0.7 and 38.84 t/ha respectively in area faces towards the sensor, whereas poor sensitivity with 0.61 and 45.58 t/ha respectively in shadowed areas. The analysis showed that the model generated without considering the slope aspect may lead to overestimation in the areas facing towards the sensor and underestimation in shadowed areas.
\end{abstract}

Keywords: ALOS-2/PALSAR-2, SAR, above ground biomass, hilly terrain, remote sensing

\section{Introduction}

As nations, enterprises, and communities look for approaches to lessen ozone harming substance discharges to address the climate change issue, there is expanding enthusiasm for the utilization of forest biomass for bio-energy to counterbalance vitality from non-renewable energy sources. In the meantime, there are increasing calls to reduce deforestation and to preserve forest lands as carbon sinks also to address the climate change issue. The amount of biomass in a forest is a result of the contrast between production through photosynthesis and utilization by respiration and harvest processes. Thus it is a useful measure for assessing changes in forest health. Forest biomass incorporates all parts of the tree, which includes the trunk along with the bark, the branches, the needles or leaves, and even the roots [1]. Because of the difficulty of collecting field survey data of subterranean biomass, the majority of previous biomass studies using remote sensing data have focused on above ground biomass (AGB). Forest biomass is additionally exceptionally applicable for issues related to global change. For instance, the role of tropical forests in global biogeochemical cycles, especially the carbon cycle and its connection to the greenhouse effect, has elevated enthusiasm for evaluating the biomass density of tropical forests. The forest biomass gives assessments of the carbon pools in forest vegetation in light of the fact that around half of it is carbon [2]. Thus, biomass represents the potential measure of carbon that can be added to the atmosphere as carbon dioxide when it is deforested. Biomass density estimates also provide the means for calculating the amount of carbon dioxide that can be expelled from the atmosphere by reforestation or by afforestation because they establish the rates of biomass generation and the upper limits for carbon sequestering.

Several approaches have been applied for forest biomass estimation. Traditionally, in-situ field measurements are the most precise strategies for estimation [3]. Nonetheless, these approaches are typically arduous, tedious and can't provide the continuous spatial distribution of biomass. Remote sensing enables the forest AGB estimation at multiple scales by providing high spatial and temporal resolution images from local to global scales. In contrast to optical data, synthetic aperture radar (SAR) data has gained importance for various remote sensing applications due to its all-weather capability and sensitivity towards geometrical and dielectric properties. In particular for AGB estimation, microwave signals can penetrate through the canopy to a certain extent and interact with the biomass whereas optical signals interact with the upper canopy of vegetation only. However, the return signal to the SAR sensor is a combined effect of sensor parameters such as wavelength, polarization and incidence angle as well as target parameters such as geometrical, structural and dielectric properties [4], [5]. Therefore, it remains a challenging task for AGB retrieval using SAR data.

[6]-[8] studies indicated that radar backscatter saturates when the level of biomass increases to a certain point. The saturation levels depend on the wavelengths (such as C, L, Pbands), polarization, incidence angle and the characteristics of vegetation stand structure and ground conditions. In a tropical forest, AGB estimation can be limited to the lower saturation levels of low as $30 \mathrm{t} / \mathrm{ha}$ at C-band, $50 \mathrm{t} / \mathrm{ha}$ at Lband and 150-200 t/ha at P-band [9]. This is because short wavelength $\mathrm{X}$ - or C-band interacts primarily with vegetation canopy elements and is appropriate for low biomass [10]. Therefore, this data has been immensely used for various agricultural applications [11], [12]. In contrast, longwavelength L- or P-band can interact with branch, trunk, and ground elements under the forest canopy, and is suitable for relatively high biomass density [13].

Most radar-based biomass estimation studies use L-band SAR data, especially the Advanced Land Observation 


\section{International Journal of Science and Research (IJSR) \\ ISSN (Online): 2319-7064 \\ Index Copernicus Value (2015): 78.96}

Satellite Phased Array L-band Synthetic Aperture Radar (ALOS PALSAR) L-band data [14], [15]. It was found that like-polarized $(\mathrm{HH} \& \mathrm{VV})$ data at longer wavelengths are more sensitive to the surface soil moisture and roughness. Whereas, cross polarized ( $\mathrm{HV} \& \mathrm{VH}$ ) data, which is mainly observed due to multiple scattering within vegetation, is sensitive towards vegetation biophysical characteristics [16]. In [17], it has observed RMSE of 18.9 t/ha for biomass estimation by using multi-polarized (HH \& HV) L-band backscatter along with plantation age. Therefore, multipolarized PALSAR data is perceived as a promising source to precisely quantify the parameters of the AGB, forest structure, tree age and carbon stock.

In [18], it was suggested that forest AGB estimation using SAR data may be reliable when topographic characteristics are taken into consideration. [19] found that L-band multipolarization SAR data were useful for AGB estimation in hilly surfaces. [20]-[23] indicated that topography influences SAR backscatter thus complicating the estimation of forest's biophysical characteristics, particularly through local incidence angle, shadowing, and effects on radar backscatter can be complex. [19] study proposed that changes in radar incidence angle caused by terrain slope can have several effects on radar image data. Therefore, inclusion of topographic data in the model is alternative to refine biomass retrieval using SAR data in hilly surfaces [24], [25].

Literature review showed that there has been limited use of PALSAR-2 data to assess the accuracy of the biomass estimation in North East India; therefore this is an opportunity to do a study using PALSAR-2 data to estimate AGB. Further the effect of slope aspect on AGB estimation using SAR data has not been quantified so far. Therefore, the main focus of this study is to analyze the influence of slope aspect on AGB estimation using dual polarized (HH \& HV) ALOS-2 PALSAR-2 data.

\section{Materials and Methods}

\subsection{Study Area}

This study was conducted in Nongkhyllem wildlife sanctuary and reserve forest located in the state of Meghalaya, India. The Nongkhyllem wildlife sanctuary (6124 ha) and Nongkhyllem reserve forest (9011 ha) are continuous. Meghalaya actually implies the 'Abode of Clouds'. As the name proposes the state is related with clouds and rains. Meghalaya's climate is very humid in nature. It is specifically impacted by the south west monsoon and the north east winter winds. Most part of the study area is covered by dense tropical evergreen forest with patches of tropical moist deciduous forest, Assam sub-tropical pine forest, semi evergreen forest, Khasi sub-tropical wet hill forest, Khasi hill sal and some jhum cultivation. The important species in the study area include Schima wallichi $(8.26 \%)$, Shorea robusta (5.37\%), Tectona grandis (4.82\%), Sterculia villosa (4.36\%), Castanopsis spp. (4.11\%), Bauhenia spp. (4.00\%), Tetramales nudiflora (3.85\%), Artocarpus loocha (3.70\%), Albizzia procera (3.53\%), Michelia champaca (3.46\%), Callicarpa arborea (3.42\%) and Miscellaneous spp.
(51.12\%) (Forest and Environment Department, Govt. of Meghalaya). The location of study area is given in Figure 1.

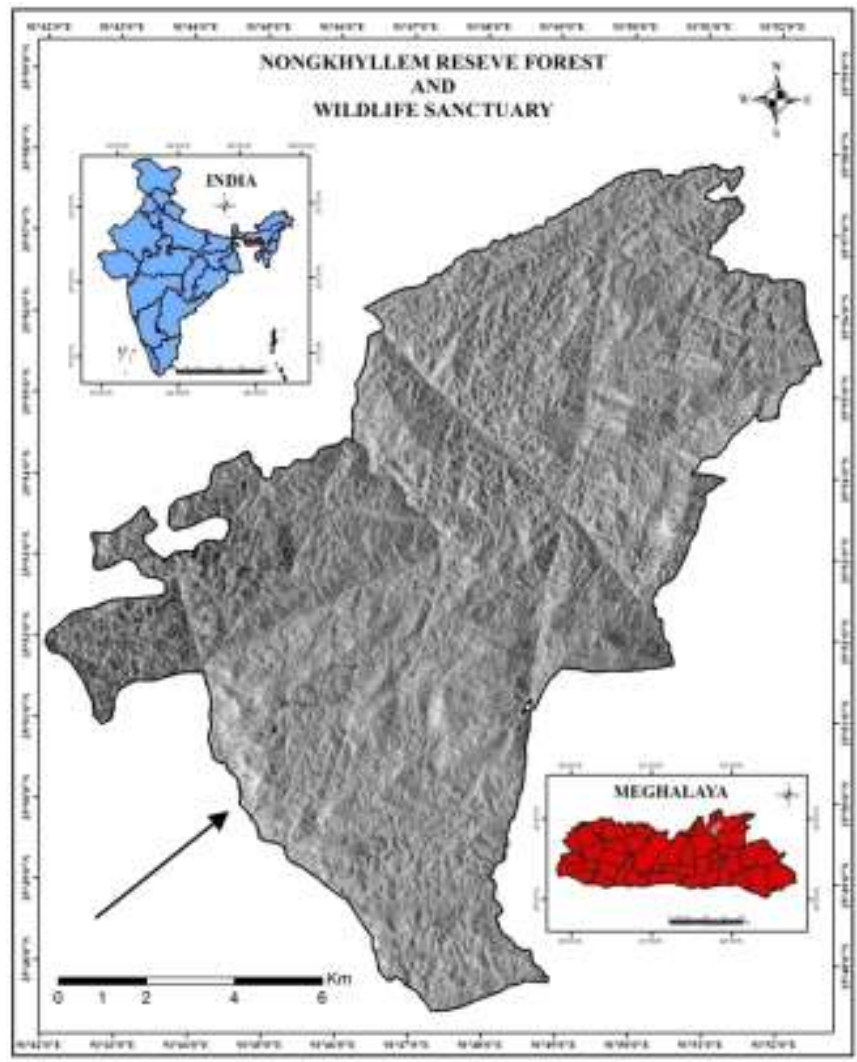

Figure 1: Study area of Nongkhyllem wildlife sanctuary and reserve forest, Meghalaya, India. ALOS-2 PALSAR-2 data with sensor look direction mentioned by arrow.

\subsection{Datasets}

Dual polarized Phased Array type L-band Synthetic Aperture Radar (PALSAR) 2 data onboard Advanced Land Observation Satellite 2 (ALOS-2), acquired by Japan Aerospace Exploration Agency (JAXA), has been used for this study. The scene was observed and captured on November 14th 2014 and processed by JAXA on April 3rd 2017 on the date of procurement. The procured PALSAR-2 image is fine beam dual polarization ( $\mathrm{HH}$ and $\mathrm{HV}$ ), with spatial resolution of $9.1 \mathrm{~m} \times 5.3 \mathrm{~m}$ (Range $\times$ Azimuth) and 24 $\mathrm{cm}$ radar wavelength. The observation mode of PALSAR-2 is strip map having observation width of $70 \mathrm{~km}$ at an off-nadir angle of $36.2^{\circ}$. In this study, SRTM 30m DEM was used to generate slope aspect information of the study and also for terrain correction of the PALSAR 2 image.

The Field inventory on individual tree based measurements at plot level was obtained from Meghalaya Forest and Environment Department (MFED). In the present study 150 sampling plots data of one hectare size from the MFED inventory database was used to estimate plot level AGB. These sampling plots have enough size to be considered for target parameters retrieval using ALOS-2 PALSAR-2 fine beam mode data [26]. Plot level AGB was estimated as sum of all individual trees within the plot. The estimated volume or growing stock using the derived volumetric equations was converted into biomass by using specific gravity as given in 
Equation (1) [27], [28].

$$
\text { Biomass (tons) }=\text { Volume }\left(m^{a}\right) \times \text { Specific gravity }
$$

\subsection{Processing}

Sentinel Application Platform (SNAP) toolbox provided by European Space Agency (ESA) has been used to generate backscattering coefficients from ALOS-2 PALSAR-2 data. Digital number in the PALSAR-2 JAXA Level 1.1 standard product is converted to backscattering coefficient using the following Equation (2) [29].

$\sigma^{\circ}=10 \log _{10}\left\langle I^{2}+Q^{2}\right\rangle+C F-A$

Where, $\sigma^{\circ}$ : Backscattering coefficient in $\mathrm{dB}$

DN: Digital number (or raw pixel value)

$\mathrm{CF} 1, \mathrm{~A}$ : Calibration factor in $\mathrm{dB}$

$\mathrm{CF} 1=-83.0 \mathrm{~dB}$ and $\mathrm{A}=32.0 \mathrm{~dB}$

In this study, Refined Lee filter of $7 \times 7$ pixel size was applied to both like polarized and cross polarized images. Due to topographical variations of a scene and the tilt of the satellite sensor, distances can be distorted in the SAR images. So, terrain corrections are intended to compensate for these distortions so that the geometric representation of the image will be as close as possible to the real world. In addition, slope aspect of the study area has been generated from SRTM 30m DEM data.

In order to analyze the effect of slope aspect on AGB estimation using SAR data, the signature of backscattering coefficients (HH \& HV) along with slope aspect have been retrieved from150 sampled plots. Due to the limitations of range doppler terrain correction, in resolving layover and shadowing, proper care has been taken in choosing the sampling locations for this study. Since the SAR data used is of $36.2^{\circ}$ incidence angle, the terrain with slope less than $36.2^{\circ}$ is suggested to minimize the effect of geometrical errors in AGB retrieval using backscattering coefficients [30]. Further correlation analysis was carried out between the AGB and the SAR backscatter coefficient of $\mathrm{HH}$ and $\mathrm{HV}$ polarized image data. The correlation coefficient values range between -1 and +1 [31]. The value -1 indicates that there is a very strong negative relationship between two variables, and +1 indicates that there is a very strong relationship between the variables. A value of 0 indicates that there is no relationship between the variables [31].

\section{Results and Discussion}

\subsection{Relationship between AGB and backscatter}

To analyze the sensitivity and relationship of backscattering coefficients towards AGB, the total 150 samples have been divided into two independent sets with 120 and 30 for relationship identification and validation respectively. In this study, regression analysis has been used to identify the relationship between backscattering coefficients and AGB. The backscatter is best fitted with logarithmic relationship with AGB, as expected from previous studies [32], [33].The scatter plot of backscattering coefficients (HH \& HV) with AGB has been given in Figure 2.

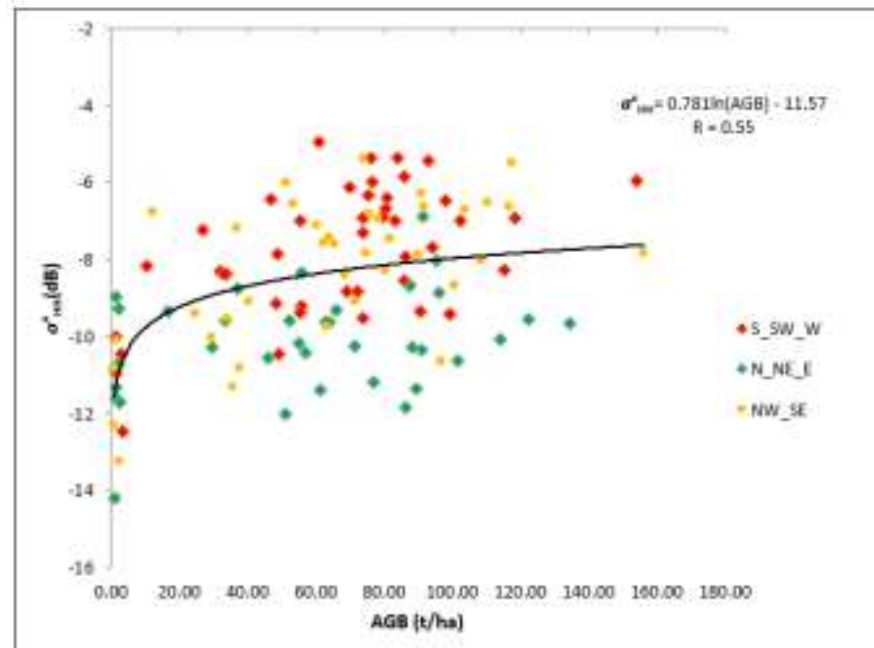

(a)

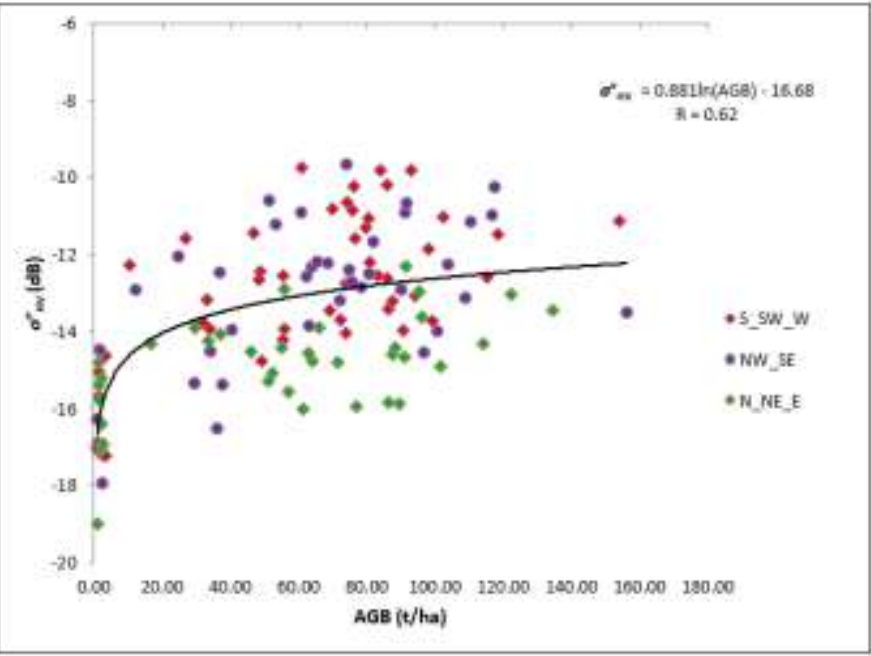

(b)

Figure 2: Scatter plot of backscattering coefficients (HH \& HV) with AGB

The results depict that HV backscatter correlates better with AGB than HH backscatter due to multiple scatterings within vegetation. It is observed that HV backscatter and AGB has $r$ and RMSE of 0.62 and $45.95 \mathrm{t} /$ ha respectively while $\mathrm{HH}$ and AGB has $\mathrm{r}$ and RMSE of 0.55 and $48.01 \mathrm{t} / \mathrm{ha}$ respectively. Numerous studies including [33]-[35] have also found stronger and positive relationship between AGB and HV backscatter. The sampled data have been segregated based on the slope aspect, which has been considered and categorized into three groups such as (a) facing towards sensor (S-SWW) (b) shadowing area (N-NE-E) and (c) facing perpendicular (NW-SE). It has been identified from the Figure 2 that most of the sampled data from N-NE-E slope aspect is falling below the trend line, whereas S-SW-W and NW-SE slope aspect samples are falling above the trend line. Thus developing a single model from the backscattering 


\section{International Journal of Science and Research (IJSR) \\ ISSN (Online): 2319-7064 \\ Index Copernicus Value (2015): 78.96}

coefficients without considering slope aspect may not give accurate and reliable estimation of biomass in hilly surfaces.

\subsection{Relationship between AGB and backscatter based on slope aspect}

To better understand the effect of slope aspect on AGB retrieval using backscattering coefficients, correlation analysis has been carried independently for three groups of slope aspects, which are facing towards sensor, shadowing area and facing perpendicular to the signal propagation i.e., S-SW-W, N-NE-E and NW-SE respectively. A schematic view of the signal propagation through vegetation in sensor facing area and shadowing area is given in Figure 3.

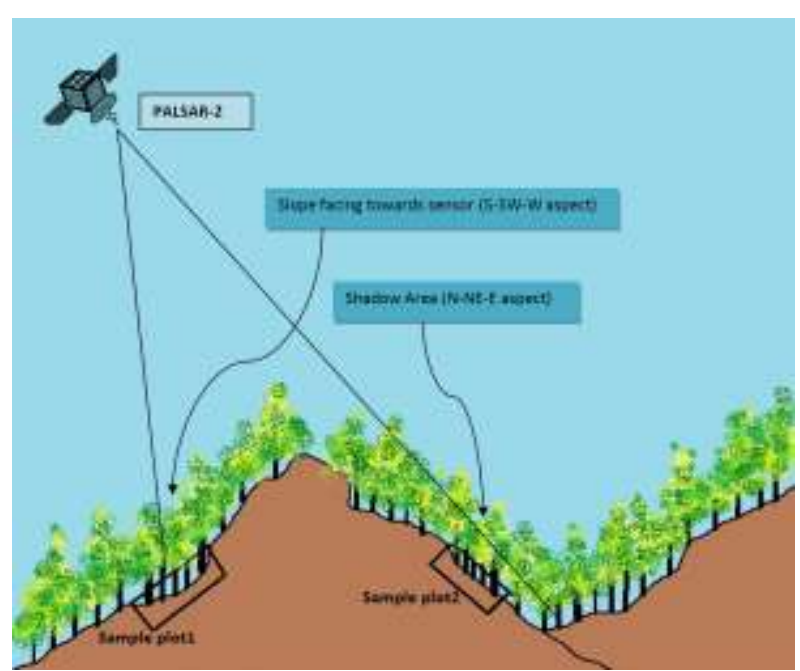

Figure 3: Schematic diagram of signal propagation through vegetation in facing towards sensor and shadowing slope aspects

\subsubsection{South-South West-West (S-SW-W)}

The S-SW-W aspect is facing towards the SAR sensor, as the data was acquired during ascending pass with antenna pointing in right direction, thus look direction was towards northeast (Figure 1). A total of 56 plots were falling in this zone, out of which 46 plots were used for analyzing the relationship while the remaining 10 plots to validate it.

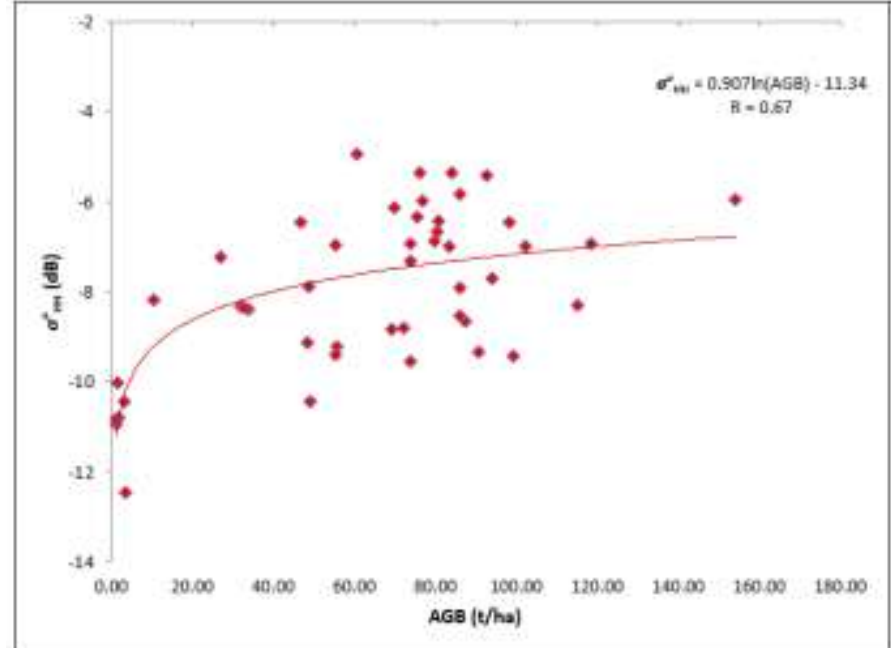

(a)

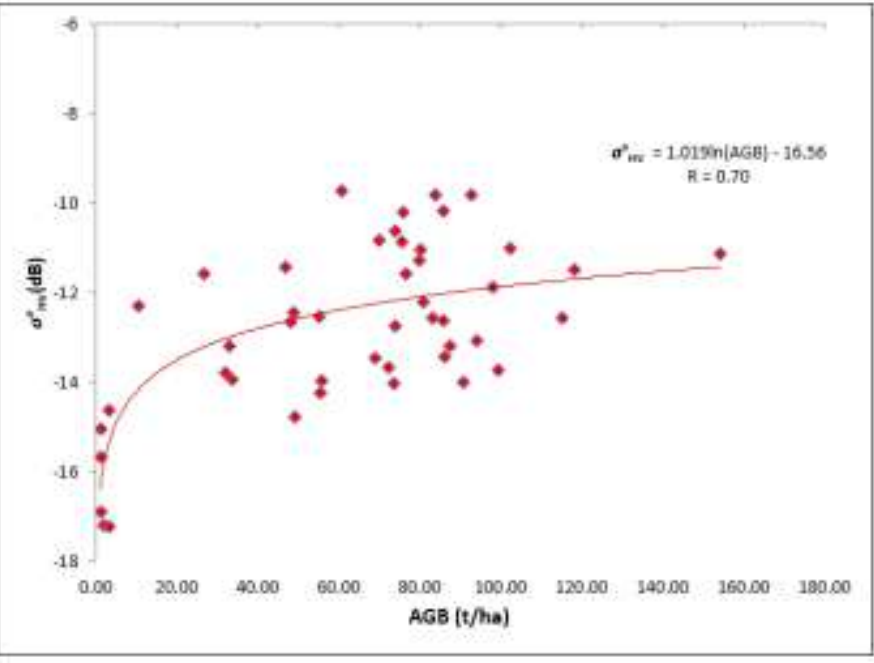

(b)

Figure 4: Scatter plot of backscattering coefficients with AGB from S-SW-W slope aspect

The backscatter values from $\mathrm{HH}$ and $\mathrm{HV}$ polarization saturates nearly at 50-60 t/ha of AGB with $-8 \mathrm{~dB}$ and $-12 \mathrm{~dB}$ respectively. The results depict that $\mathrm{HV}$ backscatter correlates better with AGB than $\mathrm{HH}$ backscatter. This analysis observed that HV backscatter and AGB has $\mathrm{r}$ and RMSE of 0.70 and $38.84 \mathrm{t} / \mathrm{ha}$ respectively, while $\mathrm{HH}$ and AGB has $r$ and RMSE of 0.67 and 49.58 t/ha respectively.

\subsubsection{North-North East-East (N-NE-E)}

The N-NE-E is in shadow area i.e. opposite to the sensor (Figure 1). A total of 46 plots were falling in this zone, of which 36 plots were used for developing the relationship while the other 10 plots to validate the same. The retrieved
$\mathrm{HV}$ and $\mathrm{HH}$ backscatter values were correlated with AGB. The results depict that HV backscatter has significantly better correlation with AGB than $\mathrm{HH}$ backscatter. The $\mathrm{HV}$ and AGB have $r$ of 0.61 while $\mathrm{HH}$ and AGB have $r$ of 0.41 . The RMSE of HV polarization was $45.58 \mathrm{t} / \mathrm{ha}$ and that of $\mathrm{HH}$ polarization was $47.48 \mathrm{t} / \mathrm{ha}$. Thus backscatter retrieved from HV polarized image was used to develop the model to estimate the AGB in N-NE-E aspect. In this zone, the backscatter values from $\mathrm{HH}$ and $\mathrm{HV}$ polarisation saturates early at 25-30 t/ha of AGB with approximately $-10 \mathrm{~dB}$ and $15 \mathrm{~dB}$ respectively.

Volume 6 Issue 6, June 2017 www.ijsr.net 


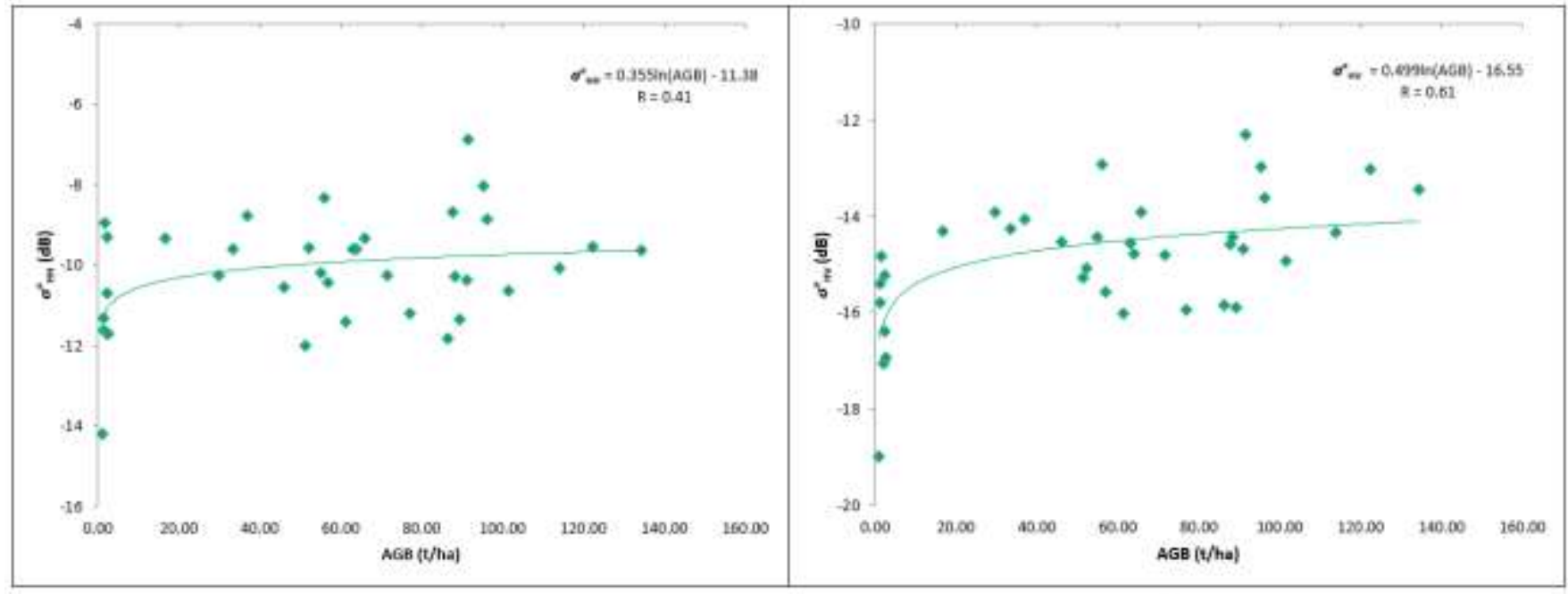

(a)

(b)

Figure 5: Scatter plot of backscattering coefficients with AGB from N-NE-E slope aspect

\subsubsection{North West-South East (NW-SE)}

From NW-SE slope aspect i.e. area facing perpendicular to the signal propagation, a total of 48 plots were falling in this zone, of which 38 plots were used for developing the relationship while the other 10 plots to validate it. The backscatter values from $\mathrm{HV}$ and $\mathrm{HH}$ polarized images were related with $\mathrm{AGB}$ and were validated also. The HV backscatter with AGB has observed $\mathrm{r}$ and RMSE of 0.66 and $43.78 \mathrm{t} /$ ha respectively while $\mathrm{HH}$ backscatter observed $\mathrm{r}$ and RMSE of 0.65 and 47.52 t/ha respectively. This study was observed backscatter behavior with AGB in NW-SE zone is more likely same as S-SW-W zone.

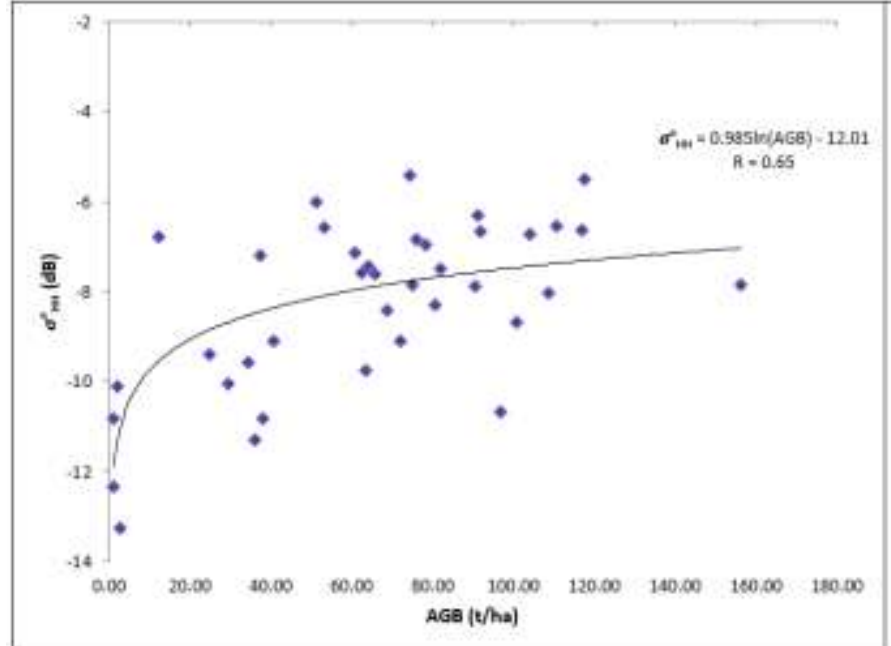

(a)

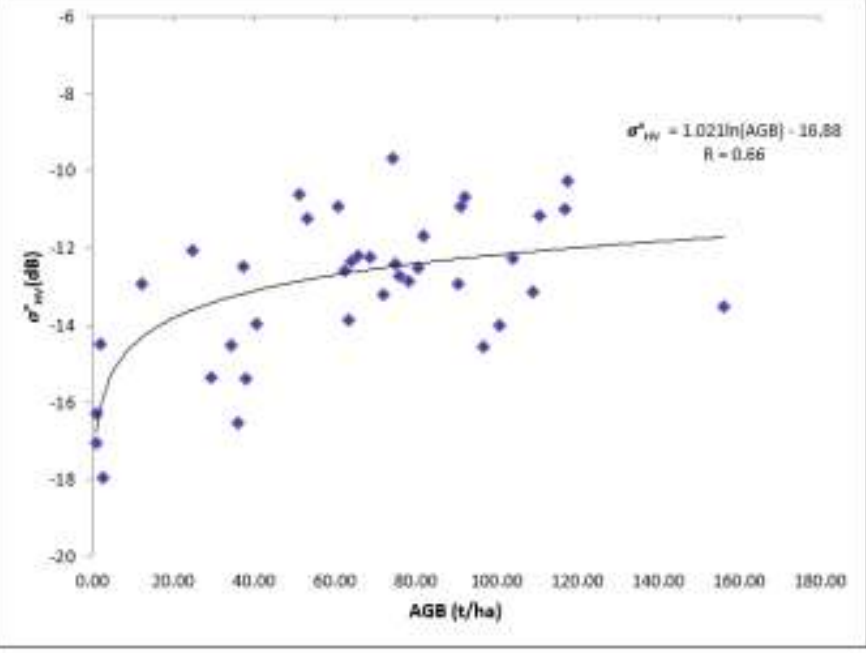

(b)

Figure 6: Scatter plot of backscattering coefficients with AGB from NW-SE slope aspect

The analysis indicated that slope aspect facing towards sensor gives higher ' $r$ ' value and lower RMSE in hilly surfaces. Since the SAR data used in this study has acquired at NE look direction, thus S-SW-W slope aspect has the higher $r$ value and lower RMSE. Whereas, N-NE-E aspect is in shadow direction thus has a lower $r$ value and higher RMSE. It is also observed that higher saturation limits of about 50-60 t/ha in S-SW-W slope aspect is due to decrease in propagation length of signal through vegetation than in flat surfaces (as shown in Figure 3). The increase in signal propagation through the vegetation in shadowing area causes the lower saturation limit of about 25-30 t/ha (as shown in Figure 3). The observed ' $r$ ' and RMSE in all the cases are given in Table 1 . In addition, a nearly $3 \mathrm{~dB}$ difference has been observed from the relationships between backscatter and AGB from sensor facing area to shadow area (Figure 7). Because of this, the model generate without considering the slope aspect may leads to overestimation in the areas facing towards the sensor and underestimation in shadowed areas. Therefore, this study suggests to choose L-band SAR data acquired over an area looking from two opposite directions for precise biomass mapping.

Volume 6 Issue 6, June 2017 www.ijsr.net 
Table 1: Results obtained in all the cases

\begin{tabular}{|c|c|c|c|c|c|}
\hline Aspect & Polarization & 'r' value & $\mathrm{N}$ & RMSE & $\mathrm{N}$ \\
\hline \multirow{2}{*}{ Combined } & $\mathrm{HV}$ & 0.62 & 120 & 45.95 & 30 \\
\cline { 2 - 6 } & $\mathrm{HH}$ & 0.55 & 120 & 48.01 & 30 \\
\hline \multirow{2}{*}{$S \_S W \_W$} & $\mathrm{HV}$ & 0.7 & 46 & 38.84 & 10 \\
\cline { 2 - 6 } & $\mathrm{HH}$ & 0.67 & 46 & 49.58 & 10 \\
\hline \multirow{2}{*}{$N W \_S E$} & $\mathrm{HV}$ & 0.66 & 38 & 43.78 & 10 \\
\cline { 2 - 6 } & $\mathrm{HH}$ & 0.65 & 38 & 47.52 & 10 \\
\hline \multirow{2}{*}{$N \_N E \_E$} & $\mathrm{HV}$ & 0.61 & 36 & 45.58 & 10 \\
\cline { 2 - 6 } & $\mathrm{HH}$ & 0.41 & 36 & 47.48 & 10 \\
\hline
\end{tabular}

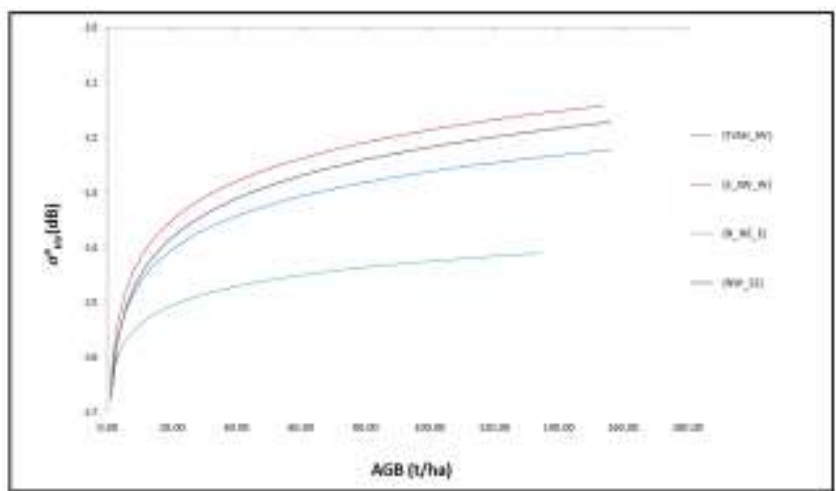

Figure 7: The relationships observed between HV backscatter and AGB

\section{Conclusion}

Forest AGB estimation and monitoring has become one of the important applications of radar remote sensing due to its higher saturation limits than in optical data. Several approaches have been developed to retrieve AGB using backscatter in flat surfaces. Whereas, these methodologies have not observed good results in hilly surfaces due to the influence of topography on SAR backscatter. Therefore, this study aims to analyze the influence of slope aspect on AGB estimation using ALOS-2 PALSAR-2 data.

This research indicated that $A G B$ retrieval is reliable in sensor facing slope of hilly surfaces with higher $r$ and lower RMSE of 0.7 and $38.84 \mathrm{t} / \mathrm{ha}$ respectively. While the shadowing zone observed lower $\mathrm{r}$ and higher RMSE of 0.61 and $45.58 \mathrm{t} / \mathrm{ha}$ respectively, which is nearly same as in the case of not considering the slope aspect. However, this study observed that backscatter from slope facing perpendicular to the signal propagation has similar behavior as in sensor facing zone. This study identified higher saturation limits of about 50-60 t/ha in sensor facing slope zone and lower saturation limit of 25-30 t/ha in shadowing zone due the influence of topography on single propagation as shown in Figure 3. Further, it was also observed that approximately 3 $\mathrm{dB}$ difference in the backscattering coefficient between sensor facing area and shadowed area having specific AGB. The analysis showed that the model generated without considering the slope aspect may lead to overestimation in the areas facing towards the sensor and underestimation in shadowed areas. Therefore, this study suggests to choose Lband SAR data acquired over an area looking from two opposite directions for precise biomass mapping.

\section{Acknowledgements}

The authors would like to thank Japan Aerospace Exploration Agency (JAXA) for ALOS-2 PALSAR-2 data provision. We acknowledge the support extended by Forest and Environment Department, Govt. of Meghalaya, India in field information sharing. The first author thanks Mr. P. Masilamani and Mr. R. Jegankumar, Department of Geography, Bharathidasan University, Tiruchirappalli for their support and fruitful discussion during this project.

\section{References}

[1] Natural

Resources

Canada, http://www.nrcan.gc.ca/forests/industry/bioproducts/13 325 (Accessed on 21/04/2017).

[2] FAO, http://www.fao.org/docrep/w4095e/w4095e04.htm (Accessed on 21/04/2017).

[3] D. Lu, "The potential and challenge of remote sensingbased biomass estimation," International Journal of Remote Sensing, 27(7), pp. 1297-1328, 2006.

[4] F.M. Henderson, A.J. Lewis, "Principles and applications of imaging radar. Manual of remote sensing: Third edition, Volume 2," United States: John Wiley and Sons, Inc., Somerset, NJ (United States), 1998.

[5] T. Sivasankar, H.S. Srivastava, P.K. Sharma, D. Kumar, P. Patel, "Study of hybrid polarimetric parameters generated from RISAT-1 SAR data for various land cover targets," International Journal of Advancement in Remote Sensing, GIS and Geography, 3(1), pp. 32-42, 2015.

[6] S. Paloscia, S. Pettinato, E. Santi, "Combining L and X band SAR data for estimating biomass and soil moisture of agricultural fields," European Journal of Remote Sensing, 45(1), pp. 99-109, 2012.

[7] H.S. Srivastava, M.L. Manchanda, S. Adiga, "Use of Radarsat SAR data in forestry (delineation of Acacia forest density)," In National Symposium on Remote Sensing for Natural Resources with Special Emphasis on Watershed Management, ISRS Symposium, Bhubaneshwar, India, 22-24 March, pp. 119-121, 2000.

[8] N.P. Joshi, E.T.A. Mitchard, J. Schumacher, V.K. Johannsen, S. Saatchi, R. Fensholt, "L-band SAR backscatter related to forest cover, height and aboveground biomass at multiple spatial scales across Denmark," Remote Sensing, 7(4), pp. 4442-4472, 2015.

[9] T. Le Toan, S. Quegan, I. Woodward, M. Lomas, N. Delbart, G. Picard, "Relating radar remote sensing of biomass to modelling of forest carbon budgets," Climatic Change, 67(2), pp. 379-402, 2004.

[10] D. Lu, Q. Chen, G. Wang, L. Liu, G. Li, E. Moran, “A survey of remote sensing-based aboveground biomass estimation methods in forest ecosystems," International Journal of Digital Earth, 9(1), pp. 63-105, 2016.

[11] G. Fontanelli, S. Paloscia, M. Zribi, A. Chahbi, "Sensitivity analysis of the X-band SAR to the wheat 


\section{International Journal of Science and Research (IJSR) \\ ISSN (Online): 2319-7064 \\ Index Copernicus Value (2015): 78.96}

and barley leaf area index in the Merguellil Basin," Remote Sensing Letters, 4(11), pp. 1107-1116, 2013.

[12] H.S. Srivastava, T. Sivasankar, P.K. Sharma, "Biophysical parameters retrieval using RISAT-1 hybrid polarimetric SAR data," National Symposium on 'Recent Advances in Remote Sensing and GIS with Special Emphasis on Mountain Ecosystems', Dehradun, India, 7-9 December, 2016.

[13] G. Patenaude, R. Milne, T.P. Dawson, "Synthesis of Remote Sensing Approaches for Forest Carbon Estimation: Reporting to the Kyoto Protocol," Environmental Science \& Policy, 8(2), pp. 161-178, 2005.

[14] A. Peregon, Y. Yamagata, "The use of ALOS/PALSAR backscatter to estimate aboveground forest biomass: a case study in Western Siberia," Remote Sensing of Environment, 137, pp. 139-146, 2013.

[15] W. Ni, G. Sun, Z. Guo, Z. Zhang, Y. He, W. Huang, "Retrieval of Forest Biomass From ALOS PALSAR Data Using a Lookup Table Method," IEEE Journal of Selected Topics in Applied Earth Observations and Remote Sensing, 6(2), pp. 875-886, 2013.

[16] K.J. Ranson, G. Sun, "Mapping biomass of a northern forest using multifrequency SAR data," IEEE Transactions on Geoscience \& Remote Sensing, 32(2), pp. 388-396, 1994.

[17] N. Baghdadi, G. Le Maire, J. Bailly, K. Ose, Y. Nouvellon, M. Zribi, C. Lemos, R. Hakamada, "Evaluation of ALOS/PALSAR L-band data for the estimation of Eucalyptus plantations aboveground biomass in Brazil," IEEE Journal of Selected Topics in Applied Earth Observations and Remote Sensing, 8 (8), pp. 3802-3811, 2015.

[18] J.M. Austin, B.G. Mackey, K.P. Van Niel, "Estimating forest biomass using satellite radar: a exploratory study in a temperate Australian Eucalyptus forest," Forest Ecology and Management, 176(1-3), pp. 575-583, 2003.

[19] G. Sun, K.J. Ranson, V.I. Kharuk, "Radiometric slope correction for forest biomass estimation from SAR data in the western Sayani Mountains, Siberia," Remote Sensing of Environment, 79 (2-3), pp. 279-287, 2002.

[20] C. Kim, "Quantiative analysis of relationship between ALOS PALSAR backscatter and forest stand volume," Journal of Marine Science and Technology, 20(6), pp. 624-628, 2012.

[21] A.J. Luckman, "The effects of topography on mechanisms of radar backscatter from coniferous forest and upland pasture," IEEE Transactions on Geoscience and Remote Sensing, 36 (5), pp. 1830-1834, 1998.

[22] Y. Rauste, "Incidence-angle dependence in forested and nonforested areas in Seasat SAR data," International Journal of Remote Sensing, 11(7), pp. 1267-1276, 1990.

[23] J.J. Van Zyl, "The effect of topography on radar scattering from vegetated areas," IEEE Transactions on Geosciences and Remote Sensing, 31(1), pp. 153-160, 1993.

[24] S.A. Soenen, D.R. Peddle, R.J. Hall, C.A. Coburn, F.G. Hall, "Estimating aboveground forest biomass from canopy reflectance model inversion in mountainous terrain," Remote Sensing of Environment, 114 (7), pp. 1325-1337, 2010.

[25] M. Main-Knorn, G.G. Moisen, S.P. Healey, W.S. Keeton, E.A. Freeman, P. Hostert," "Evaluating the remote sensing and inventory-based estimation of biomass in the Western Carpathians," Remote Sensing, 3 (7), pp. 1427-1446, 2011.

[26] P. Patel, H.S. Srivastava, "Ground truth planning for Synthetic Aperture Radar (SAR): Addressing various challenges using statistical approach," International Journal of Advancement in Remote Sensing, GIS and Geography, 1(2), pp. 1-17, 2013.

[27] S.S. Rajput, N.K. Shukla, V.K. Gupta, J.D. Jain, "Timber Mechanics: Strength Classification and Grading of timber," ICFRE Publication- 38, ICFRE, Dehradun, 1996.

[28] E.T.A. Mitchard, S.S. Saatchi, L.J.T. White, K.A. Abernethy, K.J. Jeffery, S.L. Lewis, M. Collins, M.A. Lefsky, M.E. Leal, I.H. Woodhouse, P. Meir, "Mapping tropical forest biomass with radar and spaceborne lidar in Lopé National Park, Gabon: Overcoming problems of high biomass and persistent cloud," Biogeosciences, 9(1), pp. 179-191, 2012.

[29] M. Shimada, O. Isoguchi, T. Tadono, K. Isono, "PALSAR radiometric and geometric calibration," IEEE Transactions on Geoscience and Remote Sensing, 47(12), pp. 3915-3932, 2009.

[30] J.R. Jensen, "Remote Sensing of the Environment: An Earth Resoruces Perspective," Second Edition, Prentice Hall: Upper Saddle River, NJ 07458, ISBN: 0-13188950-8, 2007.

[31] A. Stein, F. Van der Meer, B. Gorte, "Spatial Statistics for Remote Sensing: Remote sensing and digital image processing," Dordrecht, The Netherlands: Kluwer Academic Publishers, 2002.

[32] P. Patel, H.S. Srivastava, "RADARSAT-2 announcement of opportunity project on soil moisture, surface roughness and vegetation parameters retrieval using SAR polarimetry," SAC/EPSA/MPSG/CVD/TDP R\&D/01/13, SOAR International Closing and Reporting - 2013. Final report submitted to Canadian Space Agency (CSA) through MDA, Canada, Indian Space Research Organisation, India, pp. 1-81, 2013.

[33] J.M.B. Carreiras, M.J. Vasconcelos, R.M. Lucas, "Understanding the relationship between aboveground biomass and ALOS PALSAR data in the forests of Guinea-Bissau (West Africa)," Remote Sensing of Environment, 121, pp. 426-442, 2012.

[34] T. Le Toan, S. Quegan, M.W.J. Davidson, H. Balzter, P. Paillou, K. Papathanassiou, S. Plummer, F. Rocca, S. Saatchi, H. Shugart, L. Ulander, "The biomass mission: Mapping global forest biomass to better understand the terrestrial carbon cycle," Remote Sensing of Environment, 115(11), pp. 2850-2860, 2011.

[35] E.T.A Mitchard, S.S. Saatchi, I.H. Woodhouse, G. Nangendo, N.S. Ribeiro, M. Williams, C.M. Ryan, S.L. Lewis, T.R. Feldpausch, P. Meir, "Using satellite radar backscatter to predict above-ground woody biomass: A consistent relationship across four different African landscapes," Geophysical Research Letters, 36(L23401), pp. 1-6, 2009. 